\title{
PEDAGOGIA DA PRODUÇÃO DE TEXTOS: ENTRE AS QUALIDADES DISCURSIVAS, MACROPROPOSIÇÕES E REGULARIDADES
}

\author{
Pedagogía del Texto: Entre las Cualidades Discursivas, \\ Macroproposiciones y Regularidades
}

Adriano de SOUZA

Universidade Federal do Pampa

d.souzadriano@gmail.com

https://orcid.org/0000-0001-9015-465X

\begin{abstract}
RESUMO: A proposta temática deste artigo reside no diálogo que ele empreende entre os postulados sobre a produção de textos de Guedes (1994; 2009) - cuja proposta reside na elaboração de uma pedagogia da escrita baseada na produção de e na reflexão sobre narração, descrição e dissertação, com vistas ao desenvolvimento de qualidades discursivas, nomeadamente: unidade temática, concretude, questionamento $\mathrm{e}$ objetividade - e os postulados teóricos sobre o texto de Adam (2019), especialmente no que se refere ao protótipo da sequência narrativa. Com vistas a situar a presente discussão no quadro maior das pesquisas acadêmicas sobre produção de texto, o artigo apresenta um breve estado da arte de pesquisas que tratam da categoria "qualidades discursivas", em seguida, empreende duas análises de texto, procurando observar, na análise 1, o comportamento de qualidades discursivas do texto dissertativo desde o ponto de vista de suas relações, procedimentos e recursos textuais de coesão e, na análise 2, as possíveis relações entre qualidades discursivas do texto narrativo e macroproposições narrativas. Por fim, o artigo considerou o diálogo empreendido produtivo, tanto em termos de novas possibilidades de análise textual e discursiva, como em termos da construção de possibilidades outras em educação linguística e em pedagogia da escrita.
\end{abstract}

PALAVRAS-CHAVE: Qualidades discursivas; Sequência narrativa; Macroproposição narrativa; Educação linguística.

RESUMEN: La propuesta de este artículo es estabelecer un diálogo entre los postulados sobre la producción de textos de Guedes (1994; 2009), cuya propuesta establece una pedagogía de la escritura basada en la producción y la reflexión sobre la narración, la descripción y la disertación, con el objetivo de desarrollar cualidades discursivas, a saber: unidad temática, concretud, cuestionamiento y objetividad, y los postulados teóricos sobre el texto de Adam (2019), especialmente con respecto al prototipo de la secuencia narrativa. Para ubicar la discusión actual dentro del marco más amplio de la investigación académica sobre 
la producción de textos, el artículo presenta un breve estado del arte de la investigación que aborda la categoría "cualidades discursivas", luego realiza dos análisis de texto, buscando observar, en el análisis 1, el comportamiento de las cualidades discursivas del texto disertativo desde el punto de vista de sus relaciones, procedimientos y recursos textuales de cohesión y, en el análisis 2, las posibles relaciones entre las cualidades discursivas del texto narrativo y las macroproposiciones narrativas. Finalmente, el artículo consideró el diálogo emprendido productivo, tanto en términos de nuevas posibilidades para el análisis textual y discursivo, como en términos de construir posibilidades otras en la educación linguística y en la pedagogía de la escritura.

PALABRAS CLAVE: Cualidades discursivas; Secuencia narrativa; Macroproposición narrativa; Educación lingüística.

No campo do ensino de língua portuguesa, a questão do texto como objeto de ensino adquire um novo estatuto, sobretudo a partir das primeiras publicações de pesquisas sobre produção textual, especialmente Rocco (1981) e Pécora (2011 [1983]), e da coletânea de artigos organizada por Geraldi (2004 [1984]). O texto na sala de aula sistematiza uma série de postulados metodológicos e teóricos a propósito da necessidade de se mudar o enfoque do ensino de língua de uma perspectiva voltada apenas à análise de unidades isoladas, como a frase solta ou o fonema, para uma perspectiva discursiva, segundo a qual a enunciação enquanto processo sócio-histórico de produção de sentido ocuparia papel central.

É nesse panorama que podemos situar o trabalho de Guedes $(1994 ; 2009)$ e, de modo particular, sua contribuição para a construção de uma pedagogia de produção de textos pautada pela articulação entre textualidade e discursividade e, sobretudo, pautada pelo postulado segundo o qual escrever é escrever literatura brasileira, isto é, "tomar a palavra para produzir depoimentos [e conhecimentos] a respeito de sua realidade interior e de sua realidade social mais próxima." (Guedes, 1994, p. 385). Assim, ensinar a escrever é, analogamente, ensinar-se a escrever e significa, por extensão, tornar-se capaz de "produzir conhecimento a respeito de sua realidade interior e de sua realidade exterior mais próxima" (Idem, p. 389).

Com efeito, é dentro desse paradigma que o autor estabelece quatro caminhos possíveis para, em contextos de ensino e aprendizagem de línguas, 'tomar a palavra'. Esses caminhos possíveis nada mais são do que aquilo que mais tarde se convencionaria 
chamar gêneros do discurso, e que, em Guedes, significa investigação da realidade interior para produção de conhecimento relevante sobre e com a língua em situações de interação bem definidas e para leitores bem delimitados. Os mecanismos para a construção desses caminhos nascem da articulação entre, de um lado, textos assim chamados narração, descrição, dissertação e apresentação pessoal/relato de aspecto cotidiano e, de outro, a incorporação de quatro qualidades discursivas (unidade temática, concretude, objetividade e questionamento) a esses textos. Um resumo de tais postulados pode ser visto no quadro abaixo:

Quadro 1: Qualidades discursivas em função de diferentes textos em Guedes (2009)

\begin{tabular}{|c|c|}
\hline \multicolumn{2}{|c|}{ Textos de apresentação pessoal e relato de aspecto do cotidiano pessoal } \\
\hline Unidade Temática & $\begin{array}{l}\text { "É preciso escolher uma e apenas uma questão para apresentar. (...) É a } \\
\text { proposição e a tentativa de delimitação de um tema e a identificação de suas } \\
\text { partes componentes e das relações que essas partes mantêm entre si que } \\
\text { tornam interessante tanto uma conversa quanto um texto. Sem a composição } \\
\text { de um todo, sem a tentativa de estabelecer uma ordem para as coisas, não há } \\
\text { interlocução, pois o ouvinte ou leitor não vai poder confrontar a ordem } \\
\text { proposta com àquela que ele construiu para si ao aceitar o diálogo." (p. 95). }\end{array}$ \\
\hline Concretude & $\begin{array}{l}\text { "(...) é a qualidade que consiste em determinar para o leitor os significados } \\
\text { com os quais se quer que ele dialogue, e a atitude necessária ao autor que quer } \\
\text { incorporá-la a seu texto é justamente o ânimo de produzir significado em vez } \\
\text { de lidar com as palavras como se nada mais fosse possível acrescentar ao que } \\
\text { parece que todo mundo pensa que elas querem dizer." (p. 119). }\end{array}$ \\
\hline Objetividade & $\begin{array}{l}\text { "(...) é a capacidade de perceber os objetos, mais especificamente a } \\
\text { capacidade de perceber o que está lá fora e o que se passa cá dentro (...) texto } \\
\text { objetivo, para nós, não significa texto curto, nem frio e calculista, nem grosso, } \\
\text { nem cruel. Texto objetivo é o texto capaz de perceber e mostrar os objetos, ou } \\
\text { melhor, de perceber os objetos como objetos." (p. 109). } \\
\text { "(...) é a qualidade que consiste em dar ao leitor os dados necessários para que } \\
\text { ele entenda o texto apenas lendo o texto, que, se for objetivo, contém todos os } \\
\text { elementos necessários ao entendimento da mensagem.” (p. 118). }\end{array}$ \\
\hline Questionamento & $\begin{array}{l}\text { "Ao propormos (...) questionamento, estamos convocando nosso leitor a } \\
\text { participar de sua solução, a agir, a mover-se, a mobilizar suas energias } \\
\text { intelectuais." (p. 103). "Trate de um problema, de um conflito, equacione-o, } \\
\text { encaminhe-o, proponha uma solução, se tiver uma, mas uma solução útil, ao } \\
\text { alcance da mão, executável agora mesmo." (p. 120). }\end{array}$ \\
\hline \multicolumn{2}{|r|}{ Narração } \\
\hline Unidade Temática & $\begin{array}{l}\text { "A unidade temática de uma narrativa começa a se constituir na disposição de } \\
\text { contar uma história, e uma história envolve um enredo, um conflito, fatos, } \\
\text { personagens, narrador." (p. 152). }\end{array}$ \\
\hline
\end{tabular}




\begin{tabular}{|c|c|}
\hline & $\begin{array}{l}\text { "Construa a unidade temática (...) apresentando (...) a seu interlocutor que não } \\
\text { está presente uma história completa, (a) dando-lhe todas as informações } \\
\text { necessárias a respeito do enredo, do cenário, do narrador e dos demais } \\
\text { personagens, da época em que a ação se situa, para que ele possa acompanhar } \\
\text { o relato; (b) mostrando-lhe o valor que o narrador atribui aos fatos que conta; } \\
\text { (c) apresentando dados concretos para que ele possa não só avaliar a } \\
\text { adequação dos julgamentos que o narrador faz a respeito dos fatos que narra, } \\
\text { mas também fazer sua própria avaliação da história, em confronto com a sua } \\
\text { própria experiência. (...) de tudo o que aconteceu, só interessa contar aquilo } \\
\text { que converge na direção do esclarecimento da questão que vai ser } \\
\text { equacionada no texto. (p. 169). }\end{array}$ \\
\hline Concretude & $\begin{array}{l}\text { "Use as palavras que mais claramente expressem a relação que o narrador e os } \\
\text { personagens mantêm com essas ideias, instituições e atitudes. A língua está aí } \\
\text { para ser usada e não para nos cobrar submissão ao normacultês. Chame as } \\
\text { coisas pelo nome que elas têm no seu dialeto, mas não se envergonhe das } \\
\text { palavras que lhe parecem eruditas: escrever é apropriar-se da linguagem } \\
\text { escrita para pô-la a serviço do esclarecimento que se quer produzir." (p. 170). }\end{array}$ \\
\hline Objetividade & $\begin{array}{l}\text { “(...) capacidade de ver-se de fora, de selecionar um aspecto de seu jeito de ser } \\
\text { para tornar-se inteligível para o leitor.” (p. 152). (...) objetividade é a condição } \\
\text { para que uma narrativa escrita se constitua. Ela nasce de uma peculiar relação } \\
\text { que o autor precisa aprender a manter consigo mesmo: a capacidade de } \\
\text { constituir-se em narrador, de ver-se de fora, de selecionar um aspecto de seu } \\
\text { jeito de ser para tornar-se inteligível para o leitor.” (p. 168). }\end{array}$ \\
\hline Questionamento & $\begin{array}{l}\text { "O conflito (...) a própria essência da narração: se não for para contar um } \\
\text { problema, nem vale a pena (...) juntar palavras num papel." (p. 163). "Ao } \\
\text { selecionar a história que vai contar, lembre-se de que uma narrativa que ficou } \\
\text { em nossa memória tem um significado próprio que temos de descobrir, o que } \\
\text { significa tentar escolher nela a questão mais profunda entre várias questôes } \\
\text { que ela nos apresenta." (p. 170). }\end{array}$ \\
\hline \multicolumn{2}{|r|}{ Descrição } \\
\hline Unidade Temática & $\begin{array}{l}\text { "Um tema para um texto (...) só vai resultar contundente depois de um } \\
\text { trabalho de desbaste, de eliminação de toda a matéria que não contribuir para } \\
\text { o efeito pretendido sobre o leitor. A essa qualidade chamamos unidade } \\
\text { temática, que também tem a ver com ponto de vista, é preciso determinar um } \\
\text { só para não desorientar o leitor. Quem resolver apresentar dois deles, pelo } \\
\text { menos que assuma um de cada vez." (p. 210). }\end{array}$ \\
\hline Concretude & $\begin{array}{l}\text { "Objetos são mais contundentes que ideias. (...). De nada serve ao leitor dizer } \\
\text { algo como ela era bonita, porque o que ele quer saber é como ela é bonita } \\
\text { quem a acha bonita, por que padrão ela está sendo avaliada e, principalmente, } \\
\text { qual é o papel da boniteza dela no drama das personagens envolvidas na } \\
\text { história." (p. 211). } \\
\text { "Chamamos organização externa da descrição o dispositivo que situa o leitor } \\
\text { em determinado lugar para lhe dizer para onde e como deve se mover num } \\
\text { caminho que precisa fazer sentido para ele e para o que o texto quer mostrar. } \\
\text { (...) Essa organização interna da descrição se expressa no vocabulário e na } \\
\text { sintaxe, isto é, no jeito como esse vocabulário é arrumado em frases. (p. } 221- \\
\text { 222). }\end{array}$ \\
\hline
\end{tabular}




\begin{tabular}{|c|c|}
\hline Objetividade & $\begin{array}{l}\text { “[o autor] precisa deixar claro não só por que motivo tal assunto é digno de ser } \\
\text { posto num texto, mas também quem lhe atribui tal valor. É preciso estabelecer } \\
\text { claramente o ponto de vista, que é, ao mesmo tempo, (a) o lugar onde se situa } \\
\text { o narrador (e onde ele situa o leitor) para ver o que vai descrevendo a partir de } \\
\text { indicações que orientem essa descrição no espaço (...); (b) o sentimento do } \\
\text { narrador com relação ao que descreve, sentimento que o leva a atribuir valores } \\
\text { às características, comportamentos, aspecto, forma etc., daquilo que descreve; } \\
\text { (c) o conjunto de ideias pelo qual o autor se orienta para recortar seu assunto } \\
\text { em função de algum interesse de conhecimento. (p. 218). }\end{array}$ \\
\hline Questionamento & $\begin{array}{l}\text { "Só faz sentido escrever descrições se for para equacionar um problema, para } \\
\text { resolver alguma bronca pessoal ou com a questão de que trata nosso texto ou } \\
\text { com o leitor que queremos incomodar, de preferência com os dois. (...) Ponto } \\
\text { de vista é o lugar onde se coloca o narrador para apresentar seu peculiar } \\
\text { recorte do que vai descrever. É também o local onde se coloca o leitor, cujo } \\
\text { olhar quer orientar." (p. 208-209). }\end{array}$ \\
\hline \multicolumn{2}{|r|}{ Dissertação } \\
\hline Unidade Temática & $\begin{array}{l}\text { "No texto dissertativo, a unidade temática é uma qualidade ainda mais crítica } \\
\text { do que nos outros gêneros porque, se uma narração pode agradar (...) apenas } \\
\text { por um amontoado de episódios emocionantes e se uma descrição pode } \\
\text { eventualmente tornar-se interessante apenas pelo colorido e pelo inusitado da } \\
\text { cena que apresenta, não há argumento suficientemente convincente que salve } \\
\text { um texto dissertativo da necessidade de deixar bem clara para o leitor a } \\
\text { questão que está sendo tratada. Além disso, essa unidade não pode estar } \\
\text { desvinculada - dado o próprio caráter do texto dissertativo - da } \\
\text { problematização, do questionamento. Quanto mais específico for esse tema, } \\
\text { quanto mais específico for o problema levantado, maiores serão as chances de } \\
\text { o texto interessar o leitor, de puxá-lo para dentro do assunto." (p. } 296) \text {. }\end{array}$ \\
\hline Concretude & $\begin{array}{l}\text { "Fundamental para a concretude em um texto dissertativo é a clara definição } \\
\text { dos conceitos com que as questões são trabalhadas. Quando isso não é feito, o } \\
\text { leitor atribui a eles o sentido que quer e acaba lendo não o texto, mas só o que } \\
\text { já sabia a respeito do assunto." (p. 312). } \\
\text { "Fundamental para a concretude é a determinação do lugar e do tempo e das } \\
\text { demais circunstâncias em que se dão os eventos de que se fala no texto." } \\
\text { (p.317). }\end{array}$ \\
\hline Objetividade & $\begin{array}{l}\text { "Objetividade é a capacidade de perceber os objetos, as coisas e ideias como } \\
\text { algo que se coloca diante de quem as percebe na condição de existentes } \\
\text { independentemente de quem as percebe, mesmo que saibamos que essa } \\
\text { independência é uma ficção. Para ter objetividade, é necessário reconhecer a } \\
\text { existência de um conjunto de valores a partir dos quais as questões } \\
\text { particulares tomam sentido, tomar uma posição teórica, adotar um ponto de } \\
\text { vista." (p. 300). }\end{array}$ \\
\hline Questionamento & $\begin{array}{l}\text { “(...) o questionamento faz parte da natureza específica do tema do texto } \\
\text { dissertativo: ele precisa apresentar ao seu leitor um problema, uma questão } \\
\text { que possa afetá-lo, incomodá-lo, agradá-lo e propor uma solução para esse } \\
\text { problema ou equacioná-lo, mostrando o caminho pelo qual ele poderia talvez } \\
\text { ser resolvido, ou, ainda, denunciá-lo, trazendo-o ao conhecimento, à } \\
\text { consciência do leitor.” (p. 322-323). }\end{array}$ \\
\hline
\end{tabular}

Fonte: autor, a partir de Guedes (2019, grifos do autor). 


\section{BREVE ESTADO DA ARTE DE PESQUISAS SOBRE QUALIDADES DISCURSIVAS E APRESENTAÇÃO DE UMA QUESTÃO}

O desenvolvimento de qualidades discursivas - unidade temática, objetividade, concretude e questionamento - pela ótica do ensino de produção textual foi postulado por Guedes (1994; 2009) e, desde então, tem servido ao interesse de vários trabalhos acadêmicos, consolidando-se como uma pedagogia de produção do texto escrito para além do contexto em que nasceu e no qual se apresentou como resposta didática viável. Juchem (2012) faz uma boa apresentação de como se erigiram tais postulados:

Para o autor, faltava ao aluno outros leitores além do professor. $\mathrm{O}$ propósito estava em levar o aluno a "escrever como a literatura brasileira", no sentido de responder a duas questões básicas: "Quem somos nós? E em que língua vamos nos dizer quem somos nós?". Esse trabalho de resgate do exercício do discurso parte de sua prática docente no ensino médio e, depois, na universidade, da qual deriva o Manual de Redação $(1978 ; 2002)$ e, mais tarde, a elaboração de sua tese de doutorado, intitulada Ensinar português é ensinar a escrever literatura brasileira (1994). A inauguração e a repercussão de seu trabalho resultam em pressupostos para a metodologia de ensino das disciplinas de leitura e produção textual dos cursos de Letras e de Comunicação Social da UFRGS. Do terceiro capítulo de sua tese, e da revisão do Manual, advém a publicação Da Redação à Produção Textual: o ensino da escrita (2009). (JUCHEM, 2012, p. 24).

Trabalhos como os de Conceição (1999, 2000, 2004, 2016); Seganfredo (2013); Biasotto e Conceição (2015); Marques (2016); Abreu (2015); Silva (2016); Netto (2017); Pasin (2018) e Schoffen (2018) têm confirmado a pertinência dos postulados de Guedes (2009), sobretudo no que diz respeito à necessidade de se tomar o texto como um processo ao qual se incorporam os traços favorecedores de subjetividade e singularidade, na medida em que o/a autor/a-escrevente desenvolve consecutivas reescritas guiadas por uma interlocução que avalia o desenvolvimento de unidade temática, objetividade, questionamento e concretude.

Os trabalhos de Conceição $(1999,2000)$ se dedicam mais à questão do favorecimento da discursividade no processo de aprendizado do texto escrito. Nessa linha investigativa, também estão os trabalhos de Abreu (2015), Silva (2016) e Marques (2016), que se propõem a gerar dados de análise de qualidades discursivas pelo viés da teoria dos gêneros de vertente bakhtiniana. 
Em perspectiva similar de estudo, Seganfredo (2013) propõe analisar o processo de subjetividade em narrativas de universitários, articulando as qualidades discursivas com reescritas de textos. Mais voltado para o campo da formação de professores, o trabalho de Gomes (2003), se dedica à análise da intersubjetividade em enunciação escrita de professores, de onde conclui, entre outras coisas, haver certa carência de qualidades discursivas. Já Lima (2012) propõe investigar redações de candidatos a ingresso na Universidade Federal do Rio Grande do Sul, tendo como foco analítico o quesito "qualidade estilística", do qual depreende haver certa relação com a qualidade discursiva concretude de Guedes (2009).

Conceição $(2004,2016)$ se dedica à elaboração de procedimentos avaliativos de correção do texto escrito, tendo as qualidades discursivas como parâmetro de análise. Também nessa linha encontra-se o trabalho de Biasotto e Conceição (2015), que apresenta um modelo de correção de textos intitulado correção misto-discursiva, com base justamente nos critérios de qualidades discursivas de Guedes (2009). Já o trabalho de Pasin (2018) apresenta possibilidades investigativas na análise de bilhetes orientadores de reescrita em disciplina acadêmica de leitura e produção textual com metodologia de trabalho similar à sugerida por Guedes (2009). Tal pesquisa, de cunho etnográfico, permitiu, dentre outros achados, mapear os diferentes tipos de bilhetes orientadores presentes em contextos de aulas de produção textual, bem como situar a ferramenta do bilhete como importante estratégia de feedback e interlocução para reescritas de textos.

O trabalho de Schoffen (2018) elabora uma grade avaliativa com descritores de níveis de desempenho e parâmetros de avaliação com recomendações para reescrita. A grade de avaliação destaca, dentre outros fatores discursivos, os elementos de qualidade discursiva como descritores importantes para o desenvolvimento de proficiência em leitura e produção textual e também sinaliza para uma possível relação entre a utilização de "recursos linguísticos e estilísticos" e o desenvolvimento de qualidades discursivas. Para Netto (2017, p. 70), que estuda o trabalho de Guedes numa perspectiva dialógica da linguagem, relacionando seus postulados com as teorias da linguagem de Bakhtin, Bronckart e Charaudeau, a proposta de Guedes (2009) busca que as produções textuais dos alunos visem à textualidade como ponto de chegada por meio da discursividade, e não por meio de uma estrutura textual preestabelecida. 
Por outro lado, o estado da arte das pesquisas sobre qualidades discursivas com base nos postulados de Guedes (1994, 2009) parece sinalizar uma carência de pesquisas que se debrucem sobre as possíveis relações entre qualidades discursivas e os níveis micro e mesotextual. Pensando nisso e por essa razão, nas seções seguintes ensaiamos um diálogo entre tais postulados e alguns aportes da linguística do texto, especialmente a partir da teoria textual de Adam (2019) e da síntese que Antunes (2005) faz a propósito das relações, procedimentos e recursos da coesão textual.

\section{CONTRIBUIÇÕES DA TEORIA TEXTUAL DE ADAM: DIÁLOGOS POSSÍVEIS}

Se pudéssemos, como sugerido na seção acima, colocar em diálogo os postulados Guedes (2009) sobre produção de texto e as reflexões teóricas de Adam (2019), talvez, um bom ponto de partida possa ser o de sistematizar o entendimento que cada qual reserva aos fenômenos sócio-históricos e culturais implicados no ato da interação verbal e verboicônica. Tomemos, para tanto, a sistematização dos níveis de análise textual e discursiva de Adam (2019, p. 35), conforme o quadro abaixo:

Quadro 2: Níveis de análise discursiva (Adam, 2019)

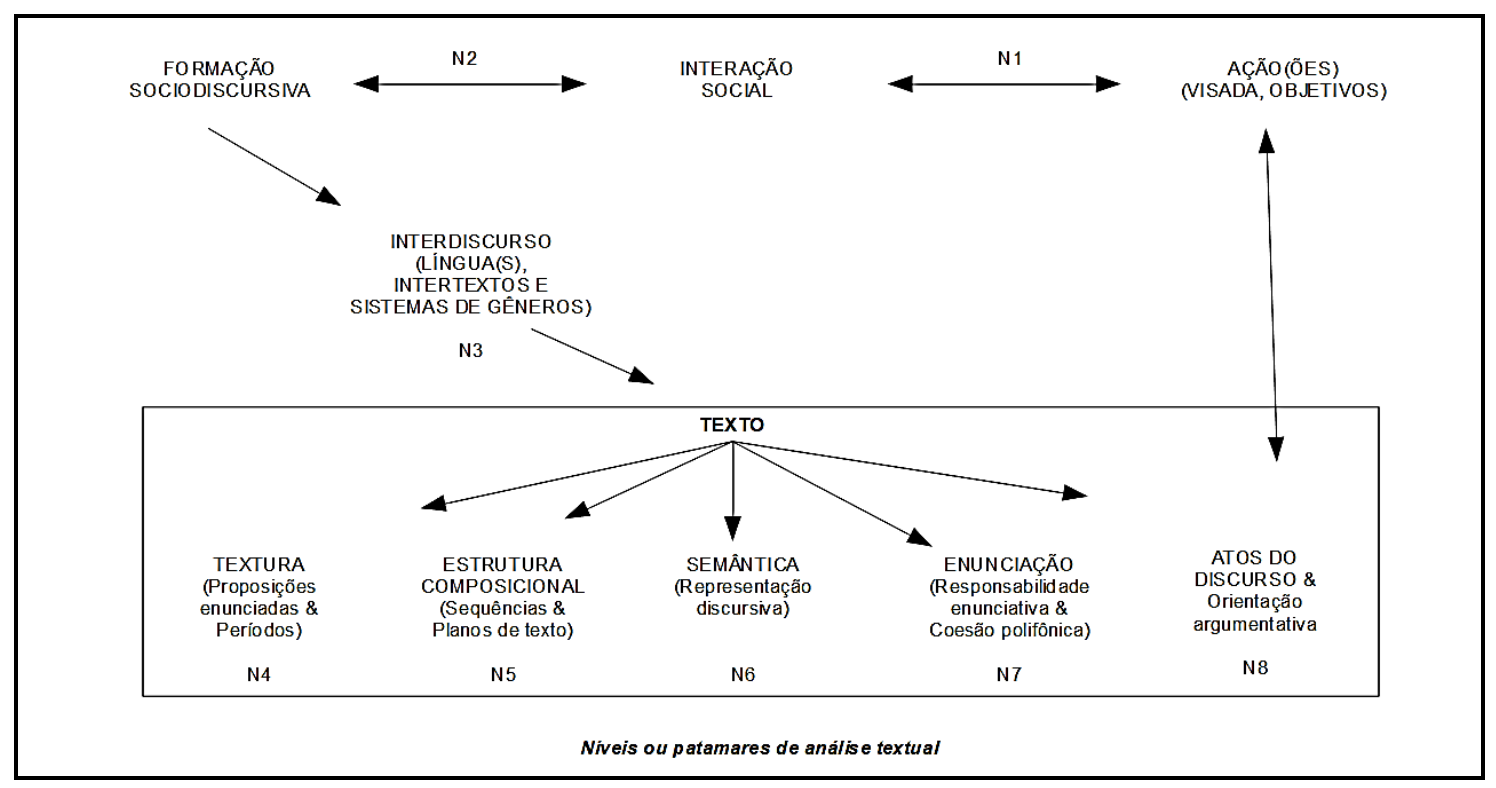

Fonte: Adam, 2019, p. 35. 
Para o linguista francês (cf. Adam, 2019, p. 35-38), a parte inferior do esquema acima integra os três componentes dos gêneros do discurso desenvolvidos por Bakhtin (2011, p. 267), a saber: composição (N6); conteúdo temático (N5) e estilo (N4). O nível N7 corresponde à ancoragem enunciativa e polifônica e, finalmente, o nível N8 e a parte superior do esquema $(\mathrm{N} 1, \mathrm{~N} 2, \mathrm{~N} 3)$ correspondem ao componente interacional da teoria social do discurso, também em termos de base bakhtiniana e voloshinoviana.

Em Guedes (1994, 2009), narração, descrição e dissertação não são propriamente sequências de base tipológica, o que, em Adam (2019), corresponde ao nível N5 do esquema. Não se trata, portanto, de pensar narração, descrição e dissertação enquanto estrutura composicional do gênero, mas como maneiras específicas de conduzir a interação social pela produção escrita e pelo tipo de conhecimento que se constrói ao narrar, descrever ou dissertar. Para Guedes (2009), salvo melhor juízo, narração, descrição e dissertação correspondem à parte superior do esquema de Adam (2019) - N1, N2 e N3 -, uma vez que integram o componente interacional de uma teoria social do discurso e, por esse componente, são também integrados.

De modo que, da maneira como se apresentam, torna-se inviável pensar os textos narrativo, descritivo e dissertativo em separado das qualidades discursivas, que lhes dão ancoragem enunciativa, isto é, que têm a função de ancorar nos enunciados textuais as respectivas coordenadas enunciativas da língua:

\begin{abstract}
Objetividade, unidade temática, concretude, questionamento são um conjunto de características que determinam a relação que o texto vai estabelecer com seus leitores por meio do diálogo que trava não só diretamente com eles, mas também com os demais textos que o antecederam na história dessa relação. (GUEDES, 2009, p. 152).
\end{abstract}

Já em Adam (2019), por outro lado, há um comprometimento teórico mais explícito (se comparado a Guedes) em termos da construção de um projeto de base teórica e analítica de amplo alcance, comprometido com a tradição de investigação acerca dos principais fenômenos textuais e discursivos e com o legado das disciplinas linguística do texto e análise do discurso. Nesse empreendimento, destaca-se um olhar atento às regularidades no nível micro e mesotextual, que permite ao autor chegar à definição de esquemas sequenciais: 
Minha hipótese é que, entre os "tipos relativamente estáveis de enunciados" e as regularidades composicionais de que fala Bakhtin, é preciso destacar as regularidades sequenciais. As sequências parecem se reduzir a alguns tipos elementares de composição de enunciados. No estado atual da teoria, eu me atenho apenas às cinco sequências prototípicas narrativa, descritiva, argumentativa, explicativa e dialogal. (Idem, p. 50).

Junto ao conceito de sequências textuais, o autor trabalha com a noção de macroposições; são conceitos análogos, já que as sequências são compostas por macroposições, isto é, unidades ligadas a outras macroposições de mesmo tipo, que ocupam posição precisa dentro da sequência e estabelecem significado mutuamente, isto é, uma macroproposição em relação a outra, e o conjunto de macroproposições compõe a sequência. Para esse autor, a sequência é "uma entidade relativamente autônoma, dotada de uma organização interna pré-formatada que (...) está em relação de dependênciaindependência com o conjunto mais amplo do qual é parte constitutiva: o texto" (Idem, p. 46). Sendo assim, diferentemente de um parágrafo, que é uma unidade composta por frases e períodos - as sequências são unidades (que se sobrepõem a frases e períodos) compostas por macroposições, que, relacionadas entre si (em nível frástico, interfrástico e transfrástico), assumem cinco formas possíveis de comportamento discursivo, a saber: narração, descrição, argumentação, explicação e diálogo.

\section{UMA ANÁLISE TEXTUAL DAS QUALIDADES DISCURSIVAS}

Nesta seção, optamos por apresentar duas análises relacionando elementos textuais ao desenvolvimento de qualidades discursivas. Na primeira análise, trabalhamos com um texto do capítulo intitulado "Dissertação" do trabalho de Guedes (2009). Nesse capítulo, há várias produções elaboradas com vistas a atender a alguma das quatro propostas de tema que constam em Guedes (2009, p. 257-258), alguns textos são modelos de boas realizações dissertativas, outros são textos com problemas em termos de qualidades discursivas. Optamos por olhar para um texto que foi destacado pelo autor como um exemplo de texto sem qualidades discursivas.

Vale mencionar que os textos que servem para exemplificar os postulados de Guedes (2009) foram reunidos ao longo de sua prática pedagógica e, a partir de um 
procedimento metodológico - melhor detalhado em Guedes (2009, p. 82-86) -, uma espécie de protocolo pactuado com a turma, dentro do qual o professor solicitava a produção de texto a partir da sugestão de um tema. Nessa dinâmica, a primeira versão do texto era feita fora do horário de aula e para ser lida ao grande grupo. Após essa leitura, seguiam-se comentários da turma e do professor, com vistas a reescritas futuras, quantas fossem necessárias. Ao fim dos encontros, o professor recolhia os textos e acrescentavalhes comentários, orientando o desenvolvimento de qualidades discursivas.

A questão analítica que propomos, na primeira análise, residiu em investigar, no texto referido, a presença (ou ausência) de relações textuais que permitissem confirmar (ou não) a razão pela qual esse texto carece de (ou contempla as) qualidades discursivas unidade temática, concretude, objetividade e questionamento. Para análise de texto em suas relações frásticas, interfrásticas e transfráticas, optamos por construir uma abordagem a partir do que Antunes (2005) define como regularidades do texto, isto é, um conjunto de propriedades textuais cujo entendimento possibilita a compreensão dos aspectos coesivos de determinada interação verbal.

Para a autora, a propriedade coesiva de um texto instaura uma continuidade semântica, que se expressa, na materialidade do texto, pelas relações de reiteração, associação e conexão. Tais relações são possíveis devido a quatro procedimentos: repetição, substituição, seleção lexical e relação sintático-semântica. Por fỉm, esses procedimentos se desdobram em diferentes recursos: paráfrase, paralelismo, repetição propriamente dita, substituição gramatical, substituição lexical, elipse (cf. Antunes, 2005, p. 51). O quadro abaixo apresenta um esquema da hipótese com que trabalhamos, em que o texto é resultado da articulação entre qualidades discursivas e regularidades textuais: 
Quadro 3: Texto - qualidades discursivas e regularidades textuais

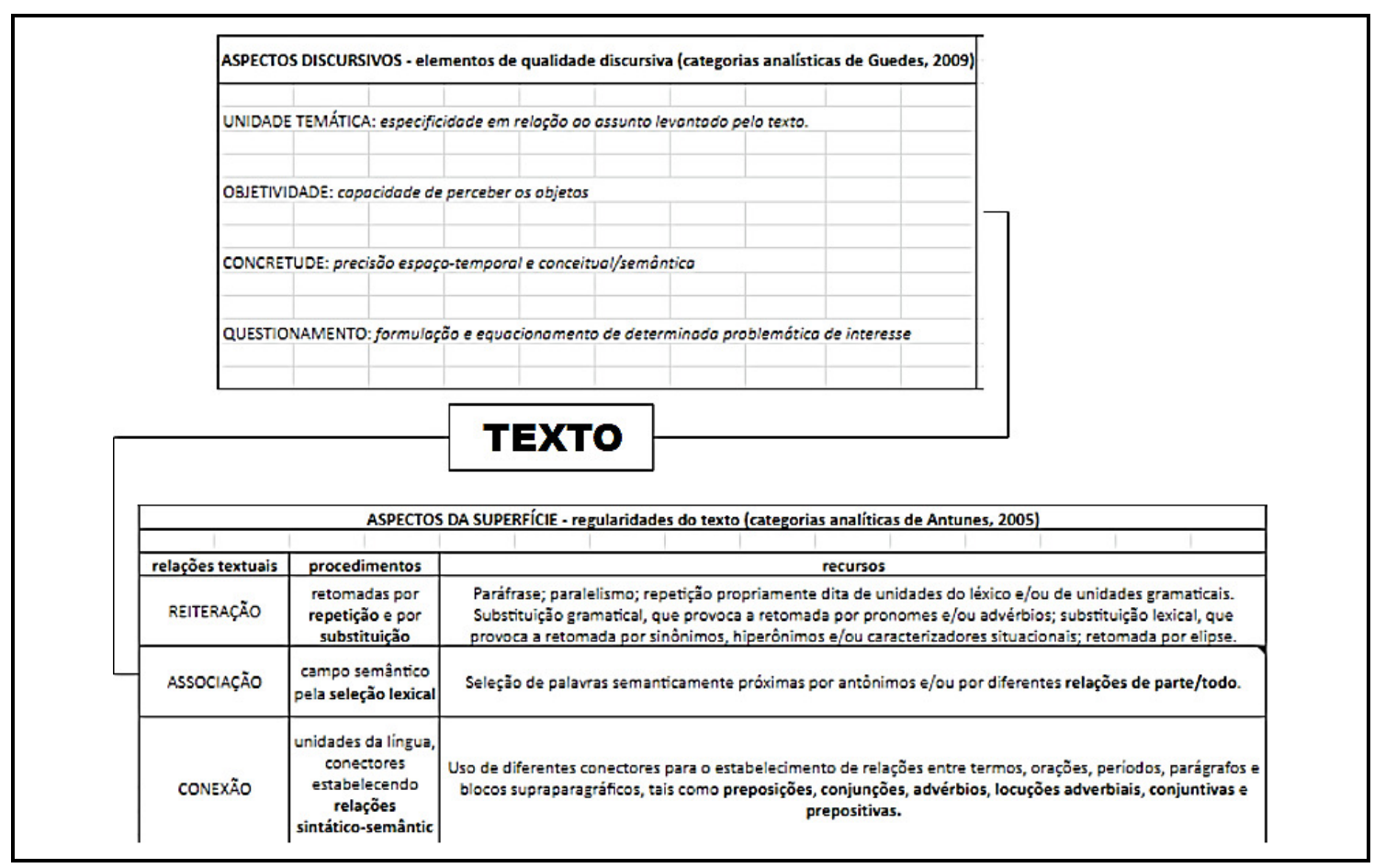

Fonte: autor.

No quadro a seguir, apresentamos o texto de que se serviu a análise aqui apresentada, seguido dos comentários elaborados por Guedes $(2009$, p. 296) a propósito da ausência de qualidades discursivas. Para tanto, o autor se valeu dos critérios mencionados no quadro 1, especificamente aqueles relacionados à "dissertação".

\section{Quadro 4: TEXTO 1}

\section{NÓS, OS SERES HUMANOS}

Se perguntássemos a um estudante quais são as partes do corpo humano, com certeza ele responderia: cabeça, tronco e membros. Somos muito mais do que isso!

Neste emaranhado de células, veias, músculos e órgãos, somos seres completos capazes de pensar, correr, pular, dormir, matar. A harmonia deste todo pode ser quebrada, se o ser humano perder um membro ou um dos sentidos, mas isso não impedirá que ele continue vivendo. As reações podem ser de revolta, angústia, e o ser humano se entregará a uma vida vegetativa. Mas sempre existem aqueles que lutam e que serão capazes de realizar coisas que um ser humano com o corpo em perfeito estado não faz.

Embora as pessoas dependam muito do corpo para serem o que desejam - atletas, bailarinos, músicos -, certamente nossa cabeça tem um papel fundamental. Nosso cérebro comandará nossas vida, nossos atos e, numa ligação íntima com nosso coração, deverá ser 
estimulado para que possamos viver com intensidade cada momento e acima de tudo fazer com que nosso coração seja mais do que o bombeador de sangue de nosso organismo, mas nosso fiel guardião de nossas mais fortes emoções.

Fonte: GUEDES (2009, p. 296-297).

Em relação a esse texto, ao examiná-lo do ponto de vista das qualidades discursivas, Guedes afirmou o seguinte:

Quanto mais específico for esse tema, quanto mais específico for o problema levantado, maiores serão as chances de o texto interessar o leitor, de puxá-lo para dentro do assunto (...). Dissertações que tentam tratar de temas amplos correm o risco de apenas repisar as generalidades mais óbvias e conhecidas a respeito do assunto ou de apenas alinhavar ideias amplas de uma posição interessante a respeito dele. O texto (...) [nós, os seres humanos], que propõe uma análise, trata, muito genérica e superficialmente, de um tema amplo demais para seu tamanho, não atingindo a unidade temática; por isso também não consegue nem concretude, nem objetividade, nem questionamento. (GUEDES, 2009, p.296).

O quadro abaixo apresenta a sistematização de alguns achados, que foram elaborados a propósito da seguinte pergunta analítica: do ponto de vista das relações textuais de reiteração, associação e conexão, por que o texto em questão "não alcança" as qualidades discursivas unidade temática, concretude, objetividade e questionamento? Para responder a essa questão, identificamos todas as relações textuais de reiteração, de associação e de conexão do texto 1, o que nos levou a catalogar tais relações em termos de procedimentos (repetição, substituição, seleção lexical e relação sintático-semântica) e de recursos utilizados (paráfrase, paralelismo, repetição propriamente dita, substituição gramatical, substituição lexical, elipse). Por fim, de posse dos dados, procuramos construir alguma relação possível entre as relações, recursos e procedimentos utilizados no texto e a ausência de qualidades discursivas. 
Quadro 5: Análise textual das qualidades discursivas do Texto 1

\section{Relações Textuais de Reiteração}

(a) Prevalecem os procedimentos de substituição, seja através de retomadas por pronome, seja por caracterizadores situacionais (léxico) ou por elipse.

(b) No parágrafo de desenvolvimento, o "grande referente" sinalizado no título "nós, os seres humanos" dá lugar a um "ele, o ser humano" e depois a um "as pessoas". Sendo a reiteração um dos procedimentos responsáveis pela continuidade do fluxo textual, não deixa de ser curioso esse deslocamento da pessoa discursiva, sobretudo porque, nesse uso está implicado, salvo melhor juízo, o principal problema da ausência de unidade temática no texto.

(c) Encontramos evidências nas relações textuais de reiteração (p.ex. a transição de "nós, os humanos" para "ele") que confirmam a falta de unidade temática no texto referido.

(d) A análise do comportamento das relações textuais de reiteração sugere que há, especialmente nos parágrafos de desenvolvimento, uma profunda relação entre os procedimentos e recursos de substituição e repetição e a unidade temática, enquanto elemento de qualidade discursiva.

\section{Relações Textuais de Associação}

(a) A escolha lexical da cadeia associativa do texto se mantém dentro dos limites semânticos esperados e fixados pelo título, pouco acrescenta ao universo de expectativas de leitura.

(b) Equivale dizer que a associação semântica construída pelo texto fica dentro de um universo associativo previsível.

(c) Ao optar por essa construção lexical, a cadeia associativa pouco contribui para a construção de um ponto de vista diferenciado em relação ao objeto (nós, os humanos).

(d) A análise apontou que a opção associativa construída pelo texto prejudicou a construção de um ponto de vista que comunicasse uma relação de singularidade com o objeto em questão.

(e) A análise da seleção lexical da cadeia associativa permite supor que seu comportamento interfere diretamente na construção da objetividade (ponto de vista pelo qual se percebe o objeto), enquanto qualidade discursiva.

\section{Relações Textuais de Conexão}

(a) Ao longo do texto, a orientação discursivo-argumentativa mobilizada pela conexão (pouco mais que 10 conectores no total) expressa relações de delimitação ou restrição; complementação; adição; finalidade; comparação ou realce e oposição.

(b) Observamos que o uso adequado de relações textuais de conexão tende a favorecer a concretude do texto.

(c) Também observamos uma relação muito próxima entre conexão e o desenvolvimento de atitudes dissertativas (comparar, analisar, classificar e definir - cf. Guedes, 2019, p. 257-258).

(e) A relação textual de conexão parece estar intrinsecamente relacionada com o desenvolvimento de qualidades discursivas de maneira geral e com a concretude, de maneira particular.

Fonte: autor. 
Nossa expectativa era que, ao fim da análise, pudéssemos mais seguramente responder a seguinte questão: considerando um contexto de ensino de produção textual,na hipótese de ter de orientar uma reescrita para o texto 1 , reescrita à qual fossem agregadas qualidades discursivas, seria possível orientá-la vinculando o desenvolvimento de unidade temática, objetividade, concretude e questionamento à cadeia de relações, procedimentos e recursos textuais de coesão? Após a análise, essa expectativa permaneceu em aberto, motivo pelo qual temos, aos poucos, nos distanciado da abordagem analítica realizada no texto 1 .

Ao que tudo indica, segundo as suposições elaboradas no quadro acima, parece haver algum vínculo mais próximo entre as relações textuais (em nível frástico, interfrástico e/ou transfrástico) de reiteração, associação e conexão e as qualidades discursivas unidade temática, concretude, questionamento e objetividade. Entretanto, qualquer conclusão a esse respeito pode ser profundamente temerária, pois apenas uma análise de um corpus mais robusto, poderá gerar dados significativos e encaminhar suposições mais assertivas, se for o caso. Além disso, ainda que se advogue no sentido da existência dessa relação e da necessidade de se explicitá-la, nos parece, ainda assim, muito pouco provável que a hipotética relação tenha qualquer efeito prático na aprendizagem e no ensino de produção textual.

Na segunda análise, trabalhamos com uma narrativa, retirada da obra Nascido do Crime (Born a Crime), texto de memórias do ator e comediante sul-africano Trevor Noah. Nessa análise, buscamos equacionar possíveis relações entre qualidades discursivas e os níveis micro e mesotextual a partir da noção de macroproposições narrativas de Adam (2019). Segundo esse autor (Idem, p. 118), para haver uma narrativa é necessário que haja “uma sucessão mínima de acontecimentos ocorrendo em um tempo $t$ depois $t+n$ ", além disso, é necessário também que haja "uma transformação de predicados ao longo do processo. A noção de processo permite precisar o componente temporal, abandonando a ideia de simples sucessão temporal dos acontecimentos." Passemos ao texto e aos comentários da análise. 
Quadro 6: TEXTO 2

[a] Em todo bairro bacana tem uma família branca que não tá nem aí pra nada. Você sabe de que tipo de família estou falando. São aqueles que não aparam a grama, não pintam a cerca, não consertam o telhado. A casa é uma espelunca. Minha mãe encontrou esse tipo de casa para comprar, [b] e foi assim que ela infiltrou uma família negra em um bairro de brancos como Highlands North.

[c] A maioria dos negros que buscavam moradia em bairros de brancos se mudava para lugares como Bramley e LombardyEast. Mas, por algum motivo, minha mãe escolheu Highlands North. Era um bairro residencial, cheio de shoppings. Classe trabalhadora, na maioria. Pessoas de classe média, estáveis, nada de ricaços. Casas antigas, mas, ainda assim, um bom lugar para viver. [d] Em Soweto, eu era a única criança branca em uma favela de negros. Em Eden Park, era o único mestiço em uma área coloured. Em Highlands North, era o único negro em um bairro de brancos - e quando digo "único" quero dizer único mesmo. [e] Em Highlands North, os brancos nunca foram embora. Era um bairro predominantemente de judeus, e judeus não abandonam seu lar. Estão cansados de fugir. Já fugiram demais. Quando chegam a um lugar, constroem uma sinagoga e ali se estabelecem. Como os brancos do bairro não pretendiam sair, não havia muitas famílias como a minha seguindo o nosso exemplo.

[f] Por muito tempo, não tive amigos em Highlands North. Para ser honesto, era mais fácil fazer amigos em Eden Park. Nos bairros de classe média, todos viviam atrás de muros. Os bairros de brancos de Johannesburgo eram construídos com base no medo - medo dos criminosos negros, medo dos levantes e da represália negra -, e, como resultado, praticamente todas as casas tinham muros de dois metros de altura e, no topo deles, cercas elétricas. Todos viviam em uma luxuosa e extravagante prisão de segurança máxima. Ninguém sentava na varanda da frente, ninguém cumprimentava os vizinhos, nenhuma criança corria de um lado para o outro entre as casas. Eu andava de bicicleta por horas pelo bairro sem encontrar nenhuma criança. Mas podia escutá-las. Estavam todas reunidas atrás dos muros de tijolinhos brincando, só que eu não era convidado. Eu ouvia as risadas brincadeiras dos vizinhos, então descia de bicicleta, escalava o muro e espiava lá dentro, onde havia várias crianças brancas nadando na piscina de alguém. [g] Eu era uma voyeur de amizade.

[h] Só depois de cerca de um ano descobri o segredo para encontrar amigos negros nos bairros residenciais: os filhos das empregadas. Muitas das empregadas domésticas na África do Sul eram demitidas quando engravidavam. Ou, se tivessem sorte, a família da casa onde trabalhavam as deixava ficar e ter o bebê, mas a criança ia morar com os parentes nas terras nativas. Assim, a mãe negra criava as crianças brancas, vendo o próprio filho apenas uma vez ao ano, durante as férias. Algumas famílias, porém, deixavam as empregadas morarem com os filhos no quartinho de empregada ou na casa dos fundos.

[i] Por muito tempo, essas crianças foram meus únicos amigos.

Fonte: NOAH, T. Nascido do Crime. Trad. Fernanda de Castro Daniel. Campinas, SP: Verus Editora; Porto Alegre, RS: TAG, 2020. p. 179-180. As letras entre colchetes foram acrescentadas.

Procedemos, em um primeiro momento, à identificação da lógica macroproposicional do estabelecimento da intriga, através da identificação dos momentos (m1, m2, m3, m4 e m5) e das macroproposições narrativas (MPn), nos termos de Adam (2019, p. 124). Assim, observamos o seguinte: 
- Situação Inicial (m1): equivale à macroproposição narrativa MPn1, trata-se do $1^{\circ}$ movimento do texto; anterior, portanto, ao começo do processo transformacional que se seguirá. No Texto 2, a MPn1 vai de de[a] até [b].

- Transformação $(\mathrm{m} 2, \mathrm{~m} 3, \mathrm{~m} 4)$ : equivale à MPn2 (macroproposição narrativa 2), também chamada 'nó da narrativa'; à MPn3 (macroproposição narrativa 3), conhecida como "coração do episódio" ou simplesmente (re)ação; à MPn4 (macroproposição narrativa 4), também chamada de desfecho ou resolução da transformação. No texto 2, a MPn2 vai de [b] até [c]; a MPn3 vai de [c] até [h] e a MPn4 vai de [h] até [i].

- Situação final (m5): equivale à MPn5 (macroproposição narrativa 5), trata-se do "depois" ou do "logo após" da transformação. No texto 2, a MPn5 vai de [i]até o ponto final.

O texto em questão trata-se, portanto, de uma sequência narrativa com cinco macroproposições compondo uma rede relacional. Dentro das macroproposições que compõem o processo transformacional da sequência narrativa, há uma sucessão de eventos episódicos (letras $c, d, e, f, g, h$ ) que poderiam ser explorados, por exemplo, como protótipos de sequência descritiva, explicativa ou até argumentativa.

Observadas as macroproposições da sequência narrativa, passamos à identificação das qualidades discursivas do texto 2, com base no que apresentamos no quadro 1 deste trabalho, especificamente no que se refere às qualidades discursivas da narração. De posse de tais informações, elaboramos o parecer que segue.

Em relação à unidade temática do texto, observamos que ela se constitui a partir de um fio narrativo que, por sua vez, se revela em consonância aos momentos m2, m3, m4, ou seja, a unidade temática do texto é o próprio processo transformacional que lhe serve de matéria narrativa. Sendo assim, a transformação - que se inicia com "e foi assim que ela infiltrou uma família negra em um bairro de brancos como Highlands North”, passa por "Por muito tempo, não tive amigos em Highlands North" e culmina em "Só depois de cerca de um ano descobri o segredo para encontrar amigos negros nos bairros residenciais" - é a própria unidade temática do texto.

É possível acrescentar ainda que à unidade temática da narrativa veicula-se o 
próprio questionamento enquanto qualidade discursiva, isso porque, sendo o questionamento o próprio conflito da narrativa e sendo a unidade temática o processo transformacional pelo qual a trama se sucede, é possível admitir que ambas as qualidades, no caso do texto narrativo, se interconectam, inter-relacionam e se retroalimentam, de modo particular, isso é o que vemos no texto 2 .

Quanto à objetividade, no caso da narração, trata-se da capacidade de constituir-se em narrador e, vendo-se de fora (objetivamente ou enquanto objeto), selecionar um aspecto e torná-lo inteligível ao leitor. No caso do texto em questão, essa qualidade é plenamente perceptível na maneira pela qual as dores de uma infância, em meio à segregação racial e às dificuldades daí decorrentes no plano das relações afetivas, são constituídas objeto de reflexão do narrador. Juntamente a esse ponto, em relação à concretude, para finalizar, diríamos que não há nada mais concreto que as descrições dos bairros de Johannesburgo e das vicissitudes infantis do personagem à procura de amigos que, ao passo que vai percebendo algumas portas se fechando e outras se abrindo à amizade, vai também percebendo que os gestos e atitudes são racializados pelo cotidiano das desiguais relações sociais.

\section{ALGUMAS ASSERÇÕES, POR FIM, A SEREM CONSIDERADAS A TÍTULO DE CONCLUSÃO}

- Se por um lado, as suposições elaboradas a partir da primeira análise não se mostraram muito produtivas para um investimento analítico capaz de apontar possíveis relações entre qualidades discursivas e os níveis micro e mesotextual; por outro lado, a análise que empreendemos do segundo texto se mostrou bastante promissora, sobretudo porque apontou que a unidade temática do texto narrativo está profundamente vinculada às macroproposições MPn2, MPn3 e Mpn4. Nesse sentido, em contextos de pedagogia de produção de texto, pode ser relevante orientar a identificação de tais macroproposições nas produções de estudantes, como estratégia didática para o desenvolvimento de qualidades discursivas na produção de reescritas.

- Além disso, a análise também apontou para um vínculo bastante próximo entre essas macroproposições (MPn2, MPn3 e Mpn4) e a qualidade discursiva questionamento, que, no texto narrativo, está bem próxima também da unidade temática. 
- Como discutimos mais acima, ainda que seja possível, por meio de um empreendimento descritivo mais robusto, inventariar as relações, os procedimentos e os recursos textuais relacionadas ao desenvolvimento de qualidades discursivas em textos de base narrativa, descritiva ou dissertativa, ainda resulta duvidoso justificar em que medida tais achados contribuiriam à pedagogia de produção de textos em Educação Básica e/ou Ensino Superior, ou seja, em que medida tais achados impactariam a aprendizagem de textos em contexto de educação formal. Por outro lado, em contextos de produção de textos com vistas à reescrita e ao acréscimo de qualidades discursivas, identificar macroproposições narrativas pode significar, em pedagogia da escrita, uma possibilidade de trabalho bastante produtiva. Resta saber se essa mesma metodologia pode ser destinada à escrita de textos com sequências argumentativas, explicativa, dialogais e/ou descritivas.

- O papel da linguística do texto para Adam (2019, p. 22) é o de "explorar e teorizar sobre esse nível intermediário (mesotextual) de estruturação, sem negligenciar o jogo complexo de restrições intrafrásticas, interfrásticas e transfrásticas, discursivas e genéricas." Nesse sentido, o trabalho que empreendemos aqui parece estar bastante próximo do escopo de trabalho e de interesse da linguística do texto. Além disso, relacionar uma abordagem discursiva a partir dos postulados de Guedes (1994; 2009) com abordagens de base textuais, seja a partir das contribuições de Antunes (2005), seja a pela abordagem de Adam (2019), se mostrou bastante promissor para trabalhos futuros.

- Em relação ao quadro 2 (níveis de análise discursiva segundo Adam, 2019, p. 35), a despeito de sua funcionalidade para compreensão das possibilidades ascendentes e descendentes de análise, ainda restam dúvidas quanto a sua funcionalidade no campo da educação linguística.

- A articulação entre os postulados de Guedes (1994; 2009) sobre produção textual e a sistematização das relações, procedimentos e recursos da coesão textual de Antunes (2005), apesar de não ter atendido às expectativas iniciais, ainda assim se mostrou profícua por vários motivos, entre os quais a observação de que texto e discurso, embora correspondam a níveis de análise e enquadres semióticos específicos, não são 
entidades autônomas, passíveis de cisão rígida, uma vez que seus limites - se definíveis - são maleáveis, porosos e plásticos.

- Por fim, a aproximação entre as abordagens de Guedes e Adam apontou para o fato de que, para elaborarem suas reflexões sobre a linguagem, mais especificamente sobre o texto, ambos os autores comungam de um mesmo ponto de partida teórico, pelo qual buscam observar o texto como prática ou processo resultante da interação social. Esse ponto de vista, digamos, sociointeracionista comum, marcadamente bakhtiniano e voloshinoviano, por outro lado, conduz ambos a posicionamentos divergentes acerca do que vem a ser narração, descrição e argumentação.

\section{REFERÊNCIAS}

ABREU, C. M. G. Gênero relatório de aula de campo: a construção da discursividade na reescrita. 102f. Dissertação (Mestrado em Letras) - Universidade Federal da Grande Dourados, Dourados, 2015.

ADAM, J. M. Textos: tipos e protótipos. Trad.: Mônica M. Cavalcante [et al]. São Paulo: Contexto, 2019.

ANTUNES, I. Lutar com palavras: coesão e coerência. São Paulo: Parábola, 2005.

BAKHTIN, M. Os gêneros do discurso. In: Estética da criação verbal. Trad.: Paulo Bezerra. 6 ed. São Paulo: Martins Fontes, 2011, p. 261- 307.

BIASOTTO, M.; CONCEIÇÃO, R. I. S. O processo de reescrita mediado pela correção: mecanismos de parafrasagem. Raído, Dourados, n. 9, v.1, p. 35-57, 2015.

CONCEIÇÃO, R. I. S. A reconstrução da discursividade na escrita: da redação escolar ao discurso. 1999. 229 f . Dissertação (Mestrado em Letras) - Universidade Federal do Rio Grande do Sul, Porto Alegre, 1999.

CONCEIÇÃO, R. I. S. Da redação escolar ao discurso: um caminho a (re)construir. Linguagem \& Ensino, v. 3, n. 2, 2000, p. 109-133.

CONCEIÇÃO, R. I. S. Correção de texto: um desafio para o professor de português. Trabalhos em Linguística Aplicada. Campinas, n. 43, n.2, p. 323-344, 2004.

CONCEIÇÃO, R. I S. Ensino da escrita: teoria e prática aplicadas à análise dialógica do discurso, à correção e à reescrita textual. In: GONÇALVES, A. V.; BUIN, E.; CONCEIÇÃO, R. I. S. [Orgs.]. Ensino de Língua Portuguesa para a contemporaneidade: escrita, leitura e formação docente. Campinas, SP : Pontes Editores, 2016. 
GERALDI, J. W. (org.). O texto na sala de aula. São Paulo: Ática, 2004. [1984].

GOMES, N. M. T. Um estudo das relações de (inter)subjetividade presentes na enunciação escrita de professores de língua materna. Tese de Doutorado. Universidade Federal do Rio Grande do Sul. Instituto de Letras. Programa de Pós-Graduação em Letras. 2003.

GUEDES, P. C. Ensinar Português é Ensinar a Escrever Literatura Brasileira. Porto Alegre, Tese Doutorado em Letras, Instituto de Letras, Pontifícia Universidade Católica do Rio Grande do Sul, 1994.

GUEDES, P. C. Da Redação à produção Textual: o ensino da escrita. São Paulo: Parábola, 2009.

JUCHEM, A. Por uma concepção enunciativa da escrita e re-escrita de textos em sala de aula: os horizontes de um hífen. Universidade Federal do Rio Grande do Sul. Instituto de Letras. Programa de Pós-Graduação em Letras. Dissertação. 2012.

LIMA, T. A. A qualidade estilística na redação do vestibular da UFRGS: o que se avalia e o que pode ser avaliado. Dissertação de Mestrado. Universidade Federal do Rio Grande do Sul. Instituto de Letras. Programa de Pós-Graduação em Letras. 2012.

MARQUES, H. F. S. C. V. Análise Comparativa da Reescrita de Sujeitos em Diferentes Níveis de Escolarização $140 \mathrm{f}$. Mestrado em Letras Instituição de Ensino: Universidade Federal da Grande Dourados, Biblioteca Depositária: Biblioteca da UFGD, 2016.

NETTO, D. F. Ensino-aprendizagem de textos argumentativos: formulando $e$ reformulando práticas de sala de aula na Educação Básica. 148 f. Doutorado em LETRAS. Instituição de Ensino: Universidade Federal do Rio Grande do Sul, Porto Alegre Biblioteca Depositária: BSCSH, 2017.

NOAH, T. Nascido do Crime. Trad.: Fernanda de Castro Daniel. Campinas, SP: Verus Editora; Porto Alegre, RS: TAG, 2020. p. 179-180.

PASIN, N. O. O bilhete orientador de reescrita a serviço da interlocução no ensino de leituras e produção textual no contexto acadêmico de letras. $181 \mathrm{f}$. Mestrado em LETRAS Instituição de Ensino: Universidade Federal do Rio Grande do Sul, Porto Alegre Biblioteca Depositária: BSCSH, 2018.

PÉCORA, A. Problemas de Redação. São Paulo: Martins Fontes, 2011 [1983].

ROCCO, M. T. F. Crise na Linguagem: a redação no vestibular. São Paulo: Mestre Jou, 1981.

SCHOFFEN, J. R. Avaliação da proficiência escrita: as qualidades discursivas e a configuração da interlocução no texto. In: Luciene Juliano Simões, Luís Augusto Fischer, Magali Lopes Endruweit. (Org.). O que eu quero dizer é o seguinte. Porto Alegre: Editora da UFRGS, 2018, v. 1, p. 297-312. 
SEGANFREDO, E. Escrita e Reescrita de Textos de Estudantes Universitários: narrativa e subjetividade. Tese de Doutorado em Letras. Universidade Federal do Rio Grande do Sul, UFRGS, Porto Alegre, RS, 2013.

SILVA, C. P. S. A Produção do Gênero Acadêmico Abstract: da Estratégia de Correção à Reescrita. 156 f. Mestrado em Letras Instituição de Ensino: Universidade Federal da Grande Dourados, Biblioteca Depositária: Biblioteca da UFGD, 2016.

Recebido em: 17 jun.2020. Aceito em: 01 set. 2020. 